\title{
COVID-19 in Cushing disease: experience of a single tertiary centre in Lombardy
}

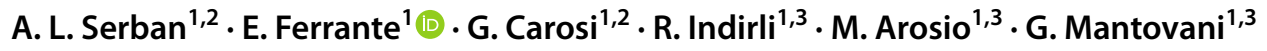

Received: 2 July 2020 / Accepted: 4 September 2020 / Published online: 11 September 2020

(C) Italian Society of Endocrinology (SIE) 2020

Coronavirus Disease 2019 (COVID-2019) has become a world-wide public health concern that severely affected Italy and especially the region of Lombardy, where a cumulative incidence of virologically-confirmed cases of $0.6 \%$ was registered by mid-April [1]. However, in this region, the rhinopharyngeal swab has been mostly performed in severely symptomatic patients referring to Emergency Rooms, thus the precise number of cases is unknown. The estimated prevalence of the novel coronavirus infection based on at least one suggestive clinical manifestation, as at early April 2020, was $19.6 \%$ [2]. Although the influenza season was ended by mid-March, at least part of the symptoms may be not COVID-19 related and, even assuming that only half are, we can presume that at least $10 \%$ in Lombardy has been affected and symptomatic. A poor prognosis of COVID-19 defined by death, invasive ventilation, or admission to Intensive Care Unit is associated to concomitant medical conditions such as hypertension and diabetes mellitus [3], comorbidities that are frequently observed in Cushing Syndrome (CS). In addition, active hypercortisolism is a known predisposing factor for infection [4]. The principal cause of endogenous CS is Cushing Disease, a rare condition with a prevalence close to 40 cases per million inhabitants [5].

In the present study we investigated the presence of typical signs and symptoms of COVID-19 and virologically confirmed disease among 61 patients with $\mathrm{CD}$ and 61 controls with pituitary microincidentalomas and normal pituitary function living in Lombardy and actively followed at Ospedale Maggiore Policlinico in Milan, Italy. The first

$\triangle$ E. Ferrante

emanuele.ferrante@policlinico.mi.it

1 Endocrinology Unit, Fondazione IRCCS Ca' Granda, Ospedale Maggiore Policlinico, 20122 Milan, Italy

2 Department of Experimental Medicine, Sapienza University of Rome, Rome, Italy

3 Department of Clinical Sciences and Community Health, University of Milan, Milan, Italy group included all the patients with confirmed CD that underwent at least one endocrinological evaluation during the last 12 months at our centre. We performed a telephone inquire that included information related to influenza vaccination, risky behaviours for COVID-19 (smoking, work, travel, cohabitants number), suggestive clinical features (fever, cough, dyspnoea, anosmia, ageusia, conjunctivitis, diarrhoea, tiredness) and COVID-19 testing, from January to mid-April 2020. All the contacted patients responded to the telephone call.

The CD group included 15 cases of active hypercortisolism, 28 patients in remission with hypoadrenalism and 18 eucortisolemic subjects. The two groups had the same mean age and gender distribution (CD 52.6 \pm 12.4 , controls $52.7 \pm 11.7$ years, female percent $83.3 \%$ in both groups). The presence of risky behaviours and influenza vaccination rate were similar in the two groups (Table 1).

We found two cases $(3.2 \%)$ of virologically confirmed COVID-19 in CD patients, but none in the control group. The first patient was a 55-year old woman in remission, with hypoadrenalism adequately treated, end-stage chronic kidney disease, and malnutrition. She was admitted in the Pulmonary Unit and treated with hydroxychloroquine, Continuous Positive Airway Pressure and hydrocortisone continuous infusion $200 \mathrm{mg} / 24 \mathrm{~h}$. Unfortunately, she died after 6 days of hospitalisation. The second, a 71-year old man with active hypercortisolism, obesity, hypertension, dyslipidaemia who discontinued metyrapone one month before because of gastrointestinal disturbances; his general state improved after one week of isolation in a non-medical structure.

Because of the small number of patients tested by nasopharyngeal swab for COVID-19 both in Lombardy (221.968/10.000.000) [1] and in our population (5/122), we also investigated the presence of characteristic signs and symptoms. Overall, almost $38 \%$ of CD and $47 \%$ of controls had at least one clinical feature between January and midApril. Considering a more specific clinical presentation as the association of fever and dry cough with other symptoms, 
Table 1 Characteristic of patients with Cushing disease and microincidentaloma in the context of COVID-19 pandemic

\begin{tabular}{|c|c|c|}
\hline & Cushing disease $N=61$ & Controls $N=61$ \\
\hline Age $(\text { years })^{\mathrm{a}}$ & $52.6 \pm 12.4$ & $52.7 \pm 11.7$ \\
\hline Females & $51(83.3 \%)$ & $51(83.3 \%)$ \\
\hline Smoking & $8(13.1 \%)$ & $11(18 \%)$ \\
\hline Influenza vaccination & $20(32.7 \%)$ & $16(26.3 \%)$ \\
\hline Profession at risk & $10(16.4 \%)$ & $7(11.5 \%)$ \\
\hline Daily travel for work & $8(13.1 \%)$ & $7(11.5 \%)$ \\
\hline $\begin{array}{l}\text { Use of public transporta- } \\
\text { tion }\end{array}$ & $2(3.2 \%)$ & $2(3.2)$ \\
\hline $\mathrm{N}^{\circ}$ of cohabitants ${ }^{\mathrm{b}}$ & $1(0-5)$ & $2(0-5)$ \\
\hline $\begin{array}{l}\mathrm{N}^{\circ} \text { cases } \mathrm{SS}^{\mathrm{C}}+: \text { Jan to } \\
15 \mathrm{Apr}\end{array}$ & $23(37.7 \%)$ & $29(47.5 \%)$ \\
\hline $\begin{array}{l}\mathrm{N}^{\circ} \text { cases } \mathrm{SS}+: \text { Mar to } \\
15 \mathrm{Apr}\end{array}$ & $9(14.7 \%)$ & $15(24.6 \%)$ \\
\hline $\mathrm{N}^{\circ} \mathrm{SS}$ : Mar to $15 \mathrm{Apr}$ & $3(1-7)$ & $2(1-6)$ \\
\hline Cough and fever & $4(6.5 \%)$ & $1(1.6 \%)$ \\
\hline $\begin{array}{l}\text { At least } 3 \mathrm{SS} \text { for } \\
1 \text { week min }\end{array}$ & $4(6.5 \%)$ & $2(3.2 \%)$ \\
\hline Nasopharyngeal swab & $2(3.2 \%)$ & $3(4.9 \%)$ \\
\hline COVID-19+ & $2(3.2 \%)$ & 0 \\
\hline
\end{tabular}

${ }^{\mathrm{a}}$ Mean \pm Standard deviation

${ }^{\mathrm{b}}$ Median (range)

${ }^{\mathrm{c}}$ Signs and symptoms

lasting for at least one week between March and mid-April (when influenza was unlikely), we found four CD patients and one subject with pituitary microincidentaloma. Three of four CD patients had active hypercortisolism: one patient had persistent $C D$ after pituitary surgery and two were newly diagnosed CD patients waiting for surgical treatment.

Our survey was conducted on a relatively small cohort of CD patients with only 15 cases of active hypercortisolism that precludes statistical conclusions. Furthermore, remote assessment did not permit an objective clinical examination and therefore under- as well as over-estimation of some symptoms cannot be excluded. Nevertheless, it shows that $3.2 \%$ of CD had confirmed COVID-19 compared with $0.6 \%$ of the general population in Lombardy by mid-April [1].
Moreover, a severe clinical presentation was observed especially in patients with active $\mathrm{CD}$, suggesting that chronic hypercortisolism may be associated with more serious SARS-CoV-2 infection. Overall, our data indicate that active CD patients should be considered as a fragile population.

\section{Compliance with ethical standards}

Conflict of interest On behalf of all authors, the corresponding author states that there is no conflict of interest.

Ethical approval The study was approved by Milan Area 2 Ethical Committee (ID 1623). The study was performed in accordance with the 1964 Declaration of Helsinki and its later amendments or comparable ethical standards.

Informed consent Informed consent was obtained from all individual participants included in the study.

\section{References}

1. EpiCentro Coronavirus-news. https://www.epicentro.iss.it/coron avirus/aggiornamenti. Accessed 30 Jun 2020

2. Negri E, Scarpino V, La Vecchia C (2020) Prevalence of COVID19-like symptoms in Italy and Lombardy, March-April 2020, and their implications on cancer prevention, diagnosis and management. Eur J Cancer Prev. https://doi.org/10.1097/CEJ.0000000000 000604

3. Guan W-J, Liang W-H, Zhao Y et al (2020) Comorbidity and its impact on 1590 patients with COVID-19 in China: a nationwide analysis. Eur Respir J. https://doi.org/10.1183/13993003.00547 $-2020$

4. Dekkers OM, Horváth-Puhó E, Jørgensen JOL et al (2013) Multisystem morbidity and mortality in Cushing's syndrome: a cohort study. J Clin Endocrinol Metab 98:2277-2284. https://doi. org/10.1210/jc.2012-3582

5. Lonser RR, Nieman L, Oldfield EH (2017) Cushing's disease: pathobiology, diagnosis, and management. J Neurosurg 126:404417. https://doi.org/10.3171/2016.1.JNS152119

Publisher's Note Springer Nature remains neutral with regard to jurisdictional claims in published maps and institutional affiliations. 